\title{
A representação do passado e a moral no século $X V$ em Portugal
}

\section{Susani Silveira Lemos França*}

O problema que conduz este texto é o da complexa articulação entre compromisso de memória e compromisso moralista na construção da verdade histórica pelos cronistas portugueses do final da Idade Média. São confrontadas passagens que mostram como não era controversa para os cronistas quatrocentistas a aproximação entre pretensão de fidelidade aos eventos e o comprometimento valorativo, pois esses dois traços funcionavam como arrimos de uma verdade construída sobre o acontecido, mas atenta ao que estava por acontecer. Para os historiadores quatrocentistas, essa conjugação era o fundamento do seu realismo e da sua verdade.

Palavras-chave: Crônicas medievais - Portugal - Moral

\section{Moral Values and the Representation of the Past in $\mathbf{1 5}^{\text {th }}$ Century Portugal} The problem which the present text investigates is the complex relationship existing between memory and morals in the construction of the historical truth by medieval Portuguese chroniclers. Several historical accounts are analyzed through a comparative perspective with the intent of showing that, for the chroniclers of the $14^{\text {th }}$ century, making value judgments and attempting a faithful representation of events was not a contradictory enterprise. On the contrary, the men believed in a 'constructed verity' regarding the past which would supposedly show what would

\footnotetext{
*Artigo recebido em junho de 2008 e aprovado para publicação em setembro de 2008.

** Professora do Departamento de História da Unesp/Franca. E-mail: susanilemos@uol.com. br.
} 
occur in the future. For $14^{\text {th }}$ century Portuguese chroniclers, then, this convergence was the basis of their realism and verity.

keywords: Middle Age Chronicles - Portugal - Moral

\section{La représentation du passé et la morale au $\mathrm{Xv}^{\mathrm{e}}$ siècle en portugal}

Le problème qui conduit cette étude est celui de la complexe articulation entre le compromis de mémoire et le compromis moraliste à la construction de l'histoire chez les chroniqueurs portuguais de la fin du Moyen Âge. Les extraits confrontés demontrent que pour ces chroniqueurs il n'y avait pas de contradiction entre la prétention de fidelité aux événements et la compromission moral, parce que ces deux traces fonctionnaient comme support d'une vérité construite à partir du vécu, mais avec attention a ce que se passerait encore. Pour les historiens du XVème, cette combinaison était la base de son realisme e de sa verité.

Mots-Clés:Moyen Age Chroniquers - Portugal - Morale

As ideias corretas são pertenças de todos (Sêneca)

He verdade que quando comecey esta ocupação de escreuer as cousas da India erão ellas tão gostosas, per suas bondades, que daua muyto contentamento ouvilas recontar; mas, porque as boas cousas pouquo durão, as bondades se forão danando e comrompendo, como ao diante direy, que nom deixarey de escreuer, pera que cada hum aja o galardão de seu bem e do mal, neste mundo nas lingoas e memorias das gentes, e no outro, ante Deos, cada hum auerá direita satisfação de seus merecimentos (Gaspar Correia, Lendas da Índia, II).

Nesse curto trecho de suas Lendas da Índia, manuscrito terminado em 1561, cujo propósito era narrar a presença portuguesa na Índia na primeira metade do século XVI, o cronista Gaspar Correia ( 1495-1561) adianta aos seus futuros leitores - então ainda parcos, mas que no futuro excederiam em muito as suas expectativas - duas funções da história que compartilhou com seus congêneres coetâneos e também com seus antecessores medievais: a conservação escrita do passado e o moralismo; funções aqui traduzidas como complementares pela promessa de recompensa negativa ou positiva, no mundo terreno pela memória, no além mundo pela justiça divina. 
Mas antes de desdobrar os fundamentos e especificidades desses dois aspectos, outros traços anunciados por esse cronista quinhentista - que, juntamente com João de Barros ( 1496-1570), Fernão Lopes de Castanheda (1500-1559) e, mais tarde, já num período de crise do projeto expansionista, Diogo do Couto ( 1542-1616), são os responsáveis pelas primeiras divulgações da expansão e cumprirão papel decisivo no longo processo de construção da imagem dos portugueses como protagonistas do alargamento do mundo merecem algumas considerações. A começar pelas oscilações na avaliação dos feitos portugueses em além-mar, oscilações marcadas pelo distanciamento da euforia otimista e orgulhosa do tempo das conquistas, quando ainda não se tinha efetivado o problema dos dispêndios e desgastes para manutenção dos lugares conquistados. ${ }^{1} \mathrm{Na}$ obra do continuador das Décadas de João de Barros, Diogo do Couto, o pessimismo com a empresa ultramarina viria a se concretizar em passagens contundentes sobre a decadência que rondava os portugueses da Índia nas proximidades do século XVII ${ }^{2}$ como em uma das cartas que envia a D. Francisco da Gama, conde da Vidigueira, na qual, lamentando sua própria sorte de historiador pouco estimado no seu tempo, diferentemente do seu antecessor João de Barros, diz: "consola-me que, pois a Índia padece tantos naufrágios e tribulações, que é justo que o seu cronista corra com ela uma mesma fortuna". ${ }^{3}$ Não tão lamentoso é Correia, mas, na sua obra, mais de quarenta anos anterior à de Couto, também já se anuncia um certo temor acerca dos rumos da expansão, pois menciona que já tinham ficado para trás os tempos em que as coisas da Índia eram "gostosas" e que "as bondades" iniciais, motivadas pelo sonho de domínio português, se tinham corrompido. ${ }^{4}$

\footnotetext{
${ }^{1}$ Entre autores que tocam nessa questão, estão clássicos como o de Fidelino de Figueiredo, A épica portuguesa no séc. XVI, Lisboa, Imprensa Nacional Casa da Moeda, 1993 e Ernani Cidade, A literatura portuguesa e a expansão ultramarina, Coimbra, Arménio Amado, 1963, p. 67-125, além de outros como o de J. S. da Silva Dias, Os descobrimentos e a problemática cultural do século XVI, Lisboa, Presença, 1988, p. 13-24.

${ }^{2}$ Vale lembrar que Diogo do Couto, em 1595, foi nomeado guarda-mor do arquivo de Goa, no tempo de Filipe I, e recebeu, como incumbência, dar continuidade às Décadas, de João de Barros. Mas é, talvez, O Soldado Prático a obra que mais o distingue dos seus antecessores, pois nela ressalta a tremenda decadência do Império, nomeadamente na Índia, e relaciona tal decadência com a derrocada material e moral da nação. Apresenta, assim, uma notável crítica ao funcionamento da administração portuguesa no Oriente, não poupando nem os escalões mais elevados, nem os mais baixos.

${ }^{3}$ Citada em Diogo do Couto, O Soldado Prático, Lisboa, Livraria Sá da Costa, 1954, p. XXII.

${ }^{4}$ Pierre Chaunu chama a atenção para como "o século XVI está, ao mesmo tempo, no apogeu e no declínio do monopólio dos ibéricos” sobre a expansão e como, nas últimas décadas do século XVI, a Europa do Norte passa da redistribuição das riquezas à participação direta na
} 
Mas o cronista, que se dispôs a "memorar as cousas da India", suscita uma outra questão relevante quando se pensa o seu próprio tempo e os já idos dos seus antecedentes avisinos: a preservação da memória no entrecruzamento entre a escrita e a fala. Ao anunciar sua motivação para escrever, ele observa que isso seria uma garantia de recompensa aos contemplados na sua escrita, porque sua reputação positiva ou negativa circularia através das falas e das lembranças das gentes. Assim, ainda que escreva em tempos de iletrados, não descarta que a sua crônica pudesse diluir-se pelas "línguas" das gentes, muito provavelmente porque eram comuns as formas de circulação oral das crônicas. ${ }^{5}$

E se é difícil avaliar o quanto as crônicas quinhentistas transitaram da forma escrita para a oral, mais difícil é pensar como o mesmo fenômeno ocorre no âmbito da produção escrita realizada na Corte de Avis (1383-1495). Vale aqui um parêntesis para lembrar que, no século XV, em Portugal, graças ao empenho dos príncipes de Avis - D. João I (1383/85-1433) e seus sucessores, D. Duarte (1433-1438), o Infante D. Pedro (1439-1448), D. Afonso V (1448-1481) e D. João II (1481-1495) -, nota-se pela primeira vez o desenvolvimento de uma atividade literária mais ou menos regular e sistemática, atividade que a historiografia e a crítica têm considerado como indicativa de um projeto de legitimação da nova dinastia, ${ }^{6}$ cujo fundador é D. João I, filho bastardo de D. Pedro I (1357-1367).

exploração. Também destaca que é entre 1480 e 1515 que o primeiro Império português, o da África e da rota das Índias, constrói-se por completo - período inicial esse que os cronistas viram de forma otimista. Cf. Pierre Chaunu, Conquista e exploração dos novos mundos (séc. XVI), Trad. Jordino Assis dos Santos Marques e Maurílio José de Oliveira Camello, São Paulo, Pioneira e Edusp, 1984, respectivamente p. 262 e 239.

${ }^{5} \mathrm{O}$ laço entre a oralidade e a escrita já foi explorado relativamente à Idade Média no conhecido texto de Paul Zumthor, La letra y la voz de la literatura medieval, Trad. Julián Presa, Madrid, Édiciones Cátedra, 1989. Relativamente ao período posterior à invenção da imprensa, o problema também tem sido explorado por historiadores como Roger Chartier, que em uma das principais teses de seus estudos defende que a oralidade está contaminada de escrita. Cf. Roger Chartier, Leitura e leitores na França do Antigo Regime, Trad. Álvaro Lorencini, São Paulo, Editora da UNESP, 2004, p. 11; Roger Chartier, Lecturas y lectores "populares" desde el Renacimiento hasta la época clásica, in: Guglielmo Cavallo e Roger Chartier, Historia de la lectura em el mundo occidental, Buenos Aires, Taurus, 2001, p. 471-493. Neste mesmo texto, Chartier cita Bernal Díaz del Castillo que, no prólogo da sua Historia verdadera de la conquista de la Nueva España, diz: "Mi historia, si se imprime, cuando la vea e oyan, la darán fe verdadeira" (p. 483).

${ }^{6}$ Cf. A. J. Saraiva, O crepúsculo da Idade Média em Portugal, Lisboa, Gradiva, 3. ed., 1993; Joaquim Veríssimo Serrão, A historiografia portuguesa. Doutrina e crítica, vol. I, Lisboa, Editorial Verbo, 1972; Luís de Souza Rebelo, A concepção do poder em Fernão Lopes, Lisboa, Livros Horizonte, 1983; Teresa Amado, Fernão Lopes, contador de História. Sobre a Crónica de D. João I, Lisboa, Editorial Estampa, 1991; J. Gouveia Monteiro, Fernão Lopes: Texto e contexto, 
Nesse projeto, não apenas foram encomendadas as crônicas que ofereceram as justificativas históricas para a mudança de dinastia, e que a seguir serão tratadas, como também foram realizadas, pelo punho dos próprios príncipes, de homens de corte ou de religiosos ligados a eles, traduções dos tesouros da erudição antiga e obras de cunho moralista e de ensinamentos técnicos, adaptadas às necessidades de uma nação que começava a se constituir. No âmbito dessa produção, a troca entre oral e escrito foi, sem dúvida, frutífera; e, no que diz respeito ao gênero em questão, são comuns tanto passagens em que os cronistas se refiram aos testemunhos que ouviram e registraram, quanto aquelas em que supõem que possam eles próprios virem a ser ouvidos. A título ilustrativo, no primeiro caso, merece destaque Gomes Eanes de Zurara (1410-1474), o segundo cronista-mor do reino e segundo guarda-mor da Torre do Tombo, a quem coube dar continuidade à tarefa iniciada por Fernão Lopes $(\sim 1378-1459$ ? $)$ de registrar os feitos portugueses passados, com destaque para a trajetória dos governantes de Avis. ${ }^{7}$ Zurara defendia explicitamente que não só em documentos, mas sobretudo nos testemunhos das pessoas que protagonizaram os feitos, encontraria a verdade essencial do passado, pois essas declarações dos envolvidos nos eventos eram vistas como caminho para a recuperação do contexto em que viveram. ${ }^{8}$ Tanto que, no segundo capítulo da Crónica do Conde D. Pedro de Menezes, afirma que, diante de feitos "tam maravilhosos" como os que ocorreram em Ceuta, com a presença dos portugueses, não teria ousado escrever se tivesse colhido informações de terceiros ou se as tivesse obtido de um número limitado de testemunhas. Assegura ainda que só o fez porque, além do que encontrou em cartas concordantes dos oficiais régios deslocados para a África, interrogou "departidamente" esses cavaleiros "e no que se todos acordavam, procedia" na sua história. ${ }^{9}$ A transposição, ainda que não contemplada em suas implicações pelo próprio cronista, foi de um registro

Coimbra, Liv. Minerva, 1988; entre outros.

${ }^{7}$ Esta questão da produção cronística na Corte de Avis é desdobrada no meu livro: S. S. L. França, Os reinos dos cronistas medievais, São Paulo, Annablume, 2006.

${ }^{8}$ As reflexões que a partir do século XX foram lançadas em torno da narrativa histórica problematizam essa crença no testemunho como duplo dos acontecimentos. O significado dos acontecimentos não se reduz à recuperação do contexto ou do testemunho direto dos envolvidos. O significado "se acha ligado à consciência retrospectiva de intérpretes historicamente situados", como aponta Arthur Danto, filósofo analítico da história. Cf. Arthur C. Danto, Historia y narracion. Ensaios de Filosofia Analitica de la Historia, Barcelona/Buenos Aires/México, Paidós, 2002, p. 22.

${ }^{9}$ G. E. de Zurara, Crónica do Conde D. Pedro de Menezes, Ed. Larry King, Lisboa, Universidade Nova de Lisboa, 1978, cap. II, p. 217. 
oral para um escrito e, considerando-se o que ele declara em outras passagens de suas crônicas, o ideal de verdade da sua escrita esteve em grande parte amparado nela, já que o contado por quem viveu era o caminho mais direto para a verdade dos acontecimentos. ${ }^{10}$ No segundo caso, à semelhança do que ocorre também entre os cronistas espanhóis, devem ser lembradas as inúmeras vezes em que Fernão Lopes usa o verbo ouvir para se dirigir ao receptor de suas crônicas, o sucessor de Zurara, Rui de Pina (1440-1522), em seu elogio das razões de se escrever história; e ao referir-se às crônicas sobre os nobres naturais de Portugal e estrangeiros, diz explicitamente que, "quando as lemos e ouvymos", somos levados a rechaçar os vícios. ${ }^{11}$

O parêntesis para tratar de assunto aparentemente alheio ao problema que conduz este texto, o da complexa articulação, na construção da verdade histórica pelos cronistas, entre o objetivo moralizante e o preceito de reprodução transparente dos eventos do passado, ${ }^{12}$ não é aleatório, pois, se é irrefutável a contaminação do oral e do escrito na construção cronística, também o é na referida articulação. Tal contaminação é, de saída, notável no jogo entre passado e presente, dado que, quando a retomada do passado surge em grande parte motivada pelos valores presentes ou visando à manutenção ou alteração desses valores, não é possível pensar a escrita nos seus limites estreitos. As narrativas e juízos dos cronistas portugueses estão perpassados pelo que leram, ouviram ou viram e, além disso, parecem projetadas no sentido de interferir nas formas de dizer, pensar e agir, como se procurará notar a seguir.

\footnotetext{
${ }^{10} \mathrm{O}$ fato mesmo de declarar que Fernão Lopes teve de desbravar cartórios, igrejas e mosteiros em busca de certidões, por ter começado a escrever os feitos de D. João I quando "muitas das pessoas que verdadeiramente sabiam eram ja partidas deste mundo, e as outras que ficarom eram departidas per o rreino", sugere que ele julgava que teria sido diferente se o seu antecessor tivesse tido a oportunidade de inquirir as pessoas que presenciaram os acontecimentos. G. E. de Zurara, Crónica da tomada de Ceuta, Ed. Francisco Maria Esteves Pereira, Coimbra, Academia das Sciencias de Lisboa, 1915, cap. III, p. 12.

11 “(...) segumdo ouvistes (...)”; “(..) ja ouvistes (...)”; “(..) teemdes ouvijdo (...)”; “(...) como ouvistes (...)” etc., respectivamente em Fernão Lopes, Crónica de D. Fernando, caps. III, IX, XVI e XXXIX; e Rui de Pina, Crônica de D. Afonso V, in: Crônicas, Ed. M. L. de Almeida, Porto, Lello \& Irmão, 1977, pr., p. 584.

${ }^{12}$ Vale lembrar que a função referencial da linguagem, desde o estruturalismo, vem sendo posta em causa por inúmeros teóricos e, mesmo que o peso da linguagem seja diferenciado entre vários autores, alguns não compartilhando a ideia de primazia do texto, é possível notar a ênfase no discurso que caracteriza a história nos últimos tempos. Sobre a questão, para não listarmos os diversos autores específicos, como Paul Veyne, Hayden White, Dominique LaCapra, Paul Ricouer etc., ver a síntese de: Georg Iggers, La Ciencia Historica en el siglo XX. Las Tendencias Actuales, Idea Universitaria, 1998, especialmente p. 98-103.
} 
Quando se observam os valores atribuídos ao fazer histórico, o aspecto geral que à primeira vista se destaca diz respeito ao caráter utilitário desse conhecimento. O testemunho de um dos tratados escritos por D. Duarte, no século XV, o Livro da Ensinança de Bem Cavalgar Toda Sela, segue justamente nesse sentido. Propõe ele que qualquer escrito deveria cumprir alguma função utilitária, fosse aperfeiçoar os homens, ensinando "bons costumes e o seguimento das virtudes", como os tratados de filosofia moral, fosse oferecer exemplos úteis para os senhores e cavaleiros em "tempos de necessidade", como os tratados sobre a guerra e as crônicas. ${ }^{13}$ Para ele, pois, a utilidade desse gênero de registro estava no seu potencial educativo para os tumultuados tempos, ou seja, para os tempos de conflitos.

Além dessa dupla função utilitária das crônicas, de respaldar juízos ou de ensinar condutas, outros testemunhos acrescentam funções talvez ainda mais relevantes, tais como o próprio estímulo às virtudes. Neste caso, a expectativa de que os feitos estariam registrados em crônicas é apontada como um sinal de que o registro histórico seria edificante, já não pelos exemplos ali registrados, mas pela tomada de consciência de que o que ainda viria a ser fixado pela escrita deveria levar a ações louváveis. Tanto o cronista Zurara quanto Duarte Galvão (1446-1517) consideram a esse respeito que a possibilidade de ser eternizado pela história poderia interferir positivamente nas condutas. $\mathrm{O}$ primeiro advoga, bem antes de Gaspar Correia mas à semelhança do que vimos na sua obra, que um dos benefícios de se preservar a memória dos homens através da história era a possibilidade de serem recompensados por suas grandes ações, pois, nas suas palavras, os homens sentir-se-iam desestimulados de se aventurarem por "grandes trabalhos e perigos, se sentissem que pelo falecimento de sua vida se acabaria toda sua relembrança...”. Já Duarte Galvão vê a história menos como recompensa e mais como inspiração, pois ele defende que as ações virtuosas seriam levadas a cabo motivadas pela expectativa de

\footnotetext{
${ }^{13}$ A dimensão pedagógica dos textos medievais já foi trabalhada por vários estudiosos, entre os quais: Mário Martins, Rodrigues Lapa e Antônio José Saraiva. Mais recentemente, uma coletânea de autores brasileiros buscou retomar esse aspecto em Lênia M. Mongelli (coord.), A Literatura na Corte de Avis, São Paulo, Martins Fontes, 2001. D. Duarte, Livro da Ensinança de Bem Cavalgar Toda Sela, edição crítica de Joseph M. Piel, Lisboa, Imprensa Nacional Casa da Moeda, 1986, cap. XV, p. 120-121, livro cuja escrita, como adianta Joseph M. Piel, foi interrompida quando o infante D. Duarte sucedeu D. João I e só foi retomado no final de sua vida (p. XII).
} 
que não seriam esquecidas, expectativa que distinguia o viver dos homens do viver dos animais. ${ }^{14}$

Mas se essas funções práticas eram ressaltadas, mais ainda o eram porque passado e presente eram indissociáveis para aqueles que então escreviam história. A verdade que perseguiram era uma verdade sustentada sobre o que foi, mas ao mesmo tempo recortada a partir de motivações do que era ou viria a ser; daí seu caráter ao mesmo tempo moralista e memorialista. ${ }^{15}$ Moralista, porque voltada para as referidas funções de espelho de virtudes, nos moldes antigos ${ }^{16}$ memorialista, porque comprometida em manter presentes acontecimentos passados. As bases da verdade, portanto, implicavam na articulação dessas duas instâncias.

Lembrar o passado na forma de crônica era, para os cronistas, buscar a verdade, e buscá-la era, antes de tudo, fazer coincidir acontecimento e palavra; ${ }^{17}$ ou seja, entendiam a verdade como repetição. Sua história realista amparavase, assim, na crença em que, através da seleção adequada e do julgamento imparcial das fontes, seria possível captar a essência dos sucessos e insucessos passados, ou melhor, na crença em que o cronista dedicado e empenhado em alcançar a verdade seria capaz de alcançar a relação perfeita dos acontecimentos ou a duplicação real dos objetos. ${ }^{18}$ Movidos por esse ideal de imitação do passado, dispuseram-se a trabalhar, como diz Fernão Lopes, com "diligência

${ }^{14}$ Respectivamente G. E. Zurara, Crónica da Tomada de Ceuta, cap. XXXVIII, p. 118 e D. Galvão, Crónica de El-Rei D. Afonso Henriques, Apresentação de José Mattoso, Lisboa, Imprensa Nacional-Casa da Moeda, 1995, prólogo, p. 1.

${ }^{15}$ Luís Felipe Barreto desdobra essa dupla dimensão das crônicas quando reflete sobre a obra de Zurara, em L. F. Barreto, "Gomes Eanes de Zurara e o nascimento do discurso historiográfico de transição", in: Descobrimentos e Renascimento. Formas de ser e pensar nos séculos XV e XVI, Lisboa, Imprensa Nacional, Casa da Moeda, 1983, p. 63-125.

${ }^{16}$ Cícero entendia a história como "mestra da vida" e esse seu caráter pedagógico justificava as imortalizações que empreendia. Nesse sentido, a história podia constituir num repertório de exemplos políticos e morais. Era a "verdade ética" que deveria estar na mira do historiador (Historia vero testis temporum, lux veritatis, vita memoriae, magistra vitae, nuntia vetustatis, qua voce alia nisi oratoris immortalitati commendatur?). Cf. M. T. Cicerón, De oratore, II, 9, 36, in: El Orador, ed. bilíngue, texto revisado e traduzido por A. Tovar e A. R. Bujaldón, Barcelona, Alma Mater, 1967.

${ }^{17}$ Nos moldes da imitatio aristotélica, em que os gêneros surgem como forma de reprodução da realidade acontecida. Cf. Aristóteles, Poética, Trad. e ed. Eudoro de Sousa, F.C.S.H. da Universidade Nova de Lisboa, I.N/C.M., "Clássicos de Filosofia”, 1986, p. 19-22. Sobre essa questão da verdade, ver também: B. Guenée, Histoire et culture historique dans l'Occident medieval, Paris, Editions Aubier-Montaigne, 1980.

${ }^{18} \mathrm{~A}$ inspiração em Tucídides merece ser aqui lembrada, pois, para este, a história devia ser registro crítico e documentado, registro do que houve, como lembra Luiz Costa Lima, História.Fiç̧ão.Literatura, São Paulo, Cia. das Letras, 2006, p. 111 e ss. 
e cuidado" e acusaram alguns congêneres de fazerem "à verdade (...) grande injuria". ${ }^{19}$ E igualmente defenderam que, sendo honestos e empenhados em selecionar testemunhos, registros aprovados por muitos e "escrituras vestidas de fé", conseguiriam relatar os acontecimentos exatamente como ocorreram, isto é, elaborar uma narrativa pura.

Muitas são as vezes em que, a despeito das flutuações nos caminhos para se buscar o essencial, os cronistas mostram-se convictos de que era esse o papel da história. Já no século anterior, o autor da Crónica Geral de Espanha de 1344 - D. Pedro de Barcelos (1287-1354), segundo Lindley Cintra -, seguindo os passos de Afonso X (1221-1284), explicitava o benefício da história de não deixar cair em esquecimento os feitos passados e lançava como louvável a ambição universalista do autor da Crónica Geral de Espanha de recontar a história da Espanha desde o "começo". ${ }^{20}$ Seduzido por esse anseio de totalidade, esse cronista não cogita - ou ao menos não dá a conhecer suas cogitações nesse sentido - que era apenas uma parte, talvez ínfima, dos acontecimentos aquela que seria registrada. Depois dele, contudo, os outros são mais sugestivos no que diz respeito à afirmação de que seu alvo era a "fidelidade" aos acontecimentos, mesmo que sob os limites de um recorte.

O autor da Crónica de $1419^{21}$ deixa outros indícios de que lhe seria possível chegar a uma verdade mais verdadeira. No final da crônica sobre Afonso Henriques, ele declara que, apesar de a idade desse rei e outros aspectos sobre ele, compilados na crônica, aparecerem em desvairados livros e de diversas maneiras, ele tinha trabalhado com "deligẽncia e cuidados de saber a verdade de cada hũa das cousas contheudas em este liuro". ${ }^{22}$ No prólogo da mesma crônica, o cronista encomenda-se ao Espírito Santo para que este o ilumine para "espreuer as vidas e muy excelentes cousas e feytos dinos de eterna memorja

${ }^{19}$ Crônicas dos Sete Primeiros Reis de Portugal, Lisboa, Academia Portuguesa da História, 1952, v. I, p. 139 e Fernão Lopes, Cronica del rei Dom João I de boa memória, Parte Primeira, Ed. Braamcamp Freire, Lisboa, Imprensa Nacional-Casa da Moeda, 1973, cap. CXLI, p. 250.

${ }^{20}$ Crónica Geral de Espanha de 1344, Ed. Luís Filipe Lindley Cintra, Lisboa, Imprensa Nacional Casa da Moeda, 1954, p. 6-7.

${ }^{21}$ Arthur de Magalhães Basto e Lindley Cintra tinham proposto a autoria de Fernão Lopes para esta crônica, todavia, uma edição crítica mais recente de Adelino de Almeida Calado questiona esta autoria. Cf. M. Basto, Estudos. Cronistas e Crônicas Antigas, Fernão Lopes e a "Crónica de 1419", Lisboa, Por ordem da Universidade, 1960; L. F. L. Cintra, Crónica Geral de Espanha de 1334, Introdução, vol. I, Lisboa, Imprensa Nacional-Casa da Moeda., 1951; A. A. Calado (ed.), Crónica de 1419, Aveiro, Universidade de Aveiro, 1998.

${ }^{22}$ Crónica de Cinco Reis de Portugal, edição diplomática de A. Magalhães Basto, Porto, Liv. Civilização, 1945, p. 134. 
dos muy exclarecidos Reis de Portugal", de modo que não "pareçam falçidades (...)". ${ }^{23}$ São recorrentes passagens indicativas de que os cronistas acreditavam poder escapar de "falsidades" e equívocos a despeito de narrarem a partir de uma perspectiva. Tal pretensão é sugerida na Crónica de D. João I, quando, por exemplo, narrando um dos confrontos entre Portugal e Castela, Fernão Lopes afirma que ninguém deveria esquivar de crer que as coisas teriam acontecido como ele narra e nem presumir que ele assim contava para "louuor dos portugueses e desfazimento de seus comtrairos, mas porque certamente assy acomteçeo de feito". ${ }^{24}$ Desse modo, ele denuncia que a certeza de que não narrava "falsidades" e de que podia chegar ao que aconteceu de fato estava no seu próprio comprometimento de historiador, embora não negligenciasse que eram muitas as incertezas com as quais tinha de lidar: versões conflitantes, falta de notícias sobre determinados pontos ou falseamento interessado da verdade. A mesma certeza é sugerida por Duarte Galvão quando afirma, no prólogo de sua crônica já do início do século XVI, ter tido de "soprir cousa de tantos tempos desordenada e falleçida" e, além de reverter a desordem, não pôde se eximir de "ememdar escpritos alheos". ${ }^{25}$

Numa outra linha de argumentação e respaldado em Marco Túlio Cícero, Zurara, na sua Crónica de Guiné, declara uma meta regulativa do seu fazer histórico: "ser lembrado de escrever verdade, e que escrevendo a verdade não minguasse dela nenhuma cousa”. E mais categórico que ele nessa crença na possibilidade de que as palavras pudessem reapresentar inteiramente os acontecimentos é Rui de Pina, pois, além de recomendar, como Fernão Lopes, a sua versão de determinado fato como aquela em que mais "verdadeiramente" se deve crer, na abertura da Crónica de D. João II, diz que o ofício de historiar "que nas letras, e na pluma consiste, (...) he assi fielmente crara luz de nossa vida, e de nossa memoria, e das cousas passadas testemunha taõ verdadeira (...). ${ }^{26}$

Tais frases estão respaldadas pela noção aristotélica, correntemente aceita no final da Idade Média, de que a história diz as coisas que sucederam,

${ }^{23}$ Crônicas dos Sete Primeiros Reis de Portugal, edição crítica de Carlos da Silva Tarouca, 3 v., Lisboa, Academia Portuguesa da História, 1952, v. I, p. 5.

${ }^{24}$ Fernão Lopes, Cronica del rei Dom João I de boa memoria. Parte Segunda, Ed. William J. Entwisle, Lisboa, Imprensa Nacional Casa da Moeda, 1977, cap. CVIII, p. 226.

${ }^{25}$ D. Galvão, Crónica de El-Rei D. Afonso Henriques, Apresentação de José Mattoso, Lisboa, Imprensa Nacional-Casa da Moeda, 1995, prólogo, p. 7.

${ }^{26}$ Zurara, Crónica de Guiné, cap. XXVII, p. 129; Rui de Pina, Crónica de D. Afonso V, cap. CXX, p. 745 e Rui de Pina, Crónica de D. João II, prólogo, p. 889. 
diferentemente da epopeia, que diz as coisas que poderiam suceder. Da mesma forma que Aristóteles não chegou a contemplar os inevitáveis entrecruzamentos entre os dois discursos, ${ }^{27}$ os cronistas temeram essas aproximações e defenderam que fazer história era o oposto a fazer fábula, pois aquela era fundada na verdade, enquanto essa tinha o seu fundamento na invenção, no fantástico, no legendário. E foi provavelmente com esse temor que Fernão Lopes disse que evitaria dizer "razoões compostas por louuor dalguuns, nem afremosentar estoria que os sessudos nom ham de crer", de forma que "destorias verdadeiras" viesse a fazer "fabullas patranhossas".

Também essas afirmações suscitam uma outra questão não menos fundamental para se entender a construção histórica desses autores: se a verdade que buscam é a verdade do acontecimento, quais os fundamentos dessa busca? Muito já se disse sobre como, a partir do século XII, a história foi usada por algumas dinastias para dar sustentação à sua política, e como, no final da Idade Média, ao conhecimento do passado veio se associar o desenvolvimento do sentimento nacional. ${ }^{29}$ Quando examinamos essas crônicas, vemos, pois, além dos acontecimentos, sobressaírem os grandes homens, suas ações políticas e administrativas, os jogos diplomáticos, a cronologia e, com destaque, a guerra. Tudo o que, de certa forma, foi atacado pela historiografia do século XX, que quis afastar-se desses princípios da história narrativa oitocentista. Quando Paul Ricouer reflete sobre esses questionamentos da história narrativa pela

${ }^{27}$ Cf. Aristóteles, Poética, p. 28-29. A título de curiosidade, é interessante lembrar que Hayden White, em suas reflexões sobre a proximidade da literatura e da história, mostrou justamente a persistência da distinção de Aristóteles até o século XIX, e a pôs em causa ao propor que não há grande ruptura epistemológica entre a história e a narrativa ficcional, nem tampouco distinção evidente entre o imaginário e o real. Cf. Hayden White, El Contenido de la forma. Narrativa, discurso y representación histórica, Bracelona, Paidós, 1992 e H. White, Trópicos do discurso: ensaios sobre a crítica da cultura, Trad. de Alípio Correia de França Neto, São Paulo, Universidade de São Paulo, 1994.

${ }^{28}$ Fernão Lopes, Cronica del rei Dom João I de boa memoria. Parte Segunda, Ed. William J. Entwisle, Lisboa, Imprensa Nacional Casa da Moeda, 1977, cap. XLII, p. 98.

${ }^{29}$ Bernard Guenée trata desses trabalhos históricos inspirados pelo poder especialmente na França, mas sem deixar de lado outras regiões, como a Espanha de Afonso X, por exemplo, no seu Histoire et culture historique dans l'Occident medieval, Paris, Editions Aubier-Montaigne, 1980, p. 332-346, e "Les Grandes Chroniques de France”, in: Les Lieux de Mémoire, Paris, Éditions Gallimard, 1997, p. 739-758. Mais recentemente, a questão foi retomada em: Joel Blanchard and Jean-Claude Mühlethaler, Écriture et Pouvoir. À l'aube des temps modernes, Paris, PUF, 2002, p. 38-39. Acerca de Portugal, entre outros autores, trataram da questão Luís de Souza Rebelo, A concepção do poder em Fernão Lopes, Lisboa, Livros Horizonte, 1983; Joaquim Veríssimo Serrão, A historiografia portuguesa. Doutrina e crítica, vol. I, Lisboa, Editorial Verbo, 1972; Teresa Amado, Fernão Lopes, contador de História. Sobre a Crónica de D. João I, Lisboa, Editorial Estampa, 1991. 
historiografia francesa do século XX, ele ressalta como o conceito de acontecimento é fundamental na discussão sobre o caráter narrativo da história, pois a incidência da crítica dessa historiografia foi sobre a "história factual", cuja base era justamente o acontecimento e seus pressupostos tácitos, a saber: a propriedade de já ter ocorrido, ser o que seres atuantes fazem acontecer ou sofrem e a ideia de alteridade absoluta. ${ }^{30}$

Entre os cronistas aqui tratados, no entanto, o que primava era o entendimento do acontecimento como aquilo que realmente aconteceu. ${ }^{31}$ A questão que emerge dessa pretensão foi motivo de reflexão no ensaio El valor de la narrativa na representação da realidade, de Hayden White, no qual o autor trata das peculiaridades das formas de narrativa histórica, anais, crônica e história, com a finalidade de perceber que tipo de realidade se visa em cada uma delas, ou melhor, que tipo de realidade é construída nos relatos realistas históricos, e de perceber a idoneidade da narrativa na representação da realidade. Como interessa, neste ensaio, sobretudo perceber que tipo de noção da realidade conduz a pretensão de descrição exata desta pelos cronistas, convém examinar algumas proposições do autor. Ele mostra como a doxa historiográfica distingue três formas de representação histórica: os anais (acontecimentos reais sem forma de relato), a crônica (que é narrativa, mas sem encerramento) e a história (que conjuga narração e análise), todas elas "produto de possíveis concepções da realidade histórica".

Os anais são, segundo o referido autor, compostos por acontecimentos extremos - nasceu, morreu, lutou etc. - e marcados por uma intenção de ordenar verticalmente, de tal forma que nem tema central, nem conclusão,

${ }^{30}$ Paul Ricoeur, "A História e a Narrativa", Tempo e Narrativa, I. Trad. Constança Marcondes Cesar, Campinas, SP, Papirus, 1994, p. 139-142.

${ }^{31}$ Esta questão, no século XX, foi atualizada sob as vestes do problema da objetividade histórica, tendo envolvido inúmeros pensadores que não cabe aqui listar. Apenas vale lembrar que William Dray mostra que a questão opõe relativistas e positivistas. Beard, Walsh e Becker, por exemplo, aproximam-se um do outro porque propuseram que o historiador sempre distorce subjetivamente a realidade objetiva e não consegue a neutralidade. Hempel defendia que o "objetivo da explicação é indicar as condições suficientes daquilo que está sendo explicado, e a suficiência dessas condições será atestada pelo fato de que o que deve ser explicado se torna dedutível daquelas condições, de acordo com leis empiricamente verificadas". Os desacordos estariam ligados não a juízos de valor, mas à deficiência de conhecimento das leis relevantes, cuja determinação também não se deve a juízo de valor, como quiseram aqueles, mas a uma avaliação indutiva de probabilidade, o que vale também para a determinação dos fatos: sustentar a partir de leis empíricas que os conhecimentos devem ter ocorrido. Cf. William H Dray, Filosofia da História. Trad. Octanny Silveira da Mota e Leonidas Hegenberg, Rio de Janeiro, Zahar Editores, 1969, p. 36-39. 
nem um princípio avaliativo da significação dos acontecimentos fazem parte dos seus possíveis, como ocorre em relatos organizados horizontalmente. O fio condutor do relato dos anais é a própria sequência dos anos, e o tipo de realidade visada por ele era firmada por essa sequência cronológica. Já a crônica, ainda que caracterizada por um relato que não alcança a postura crítica que viria a caracterizar a história, é movida por um princípio ordenador "metafísico" que não demandava justificação teórica, o próprio criador $;^{32}$ um princípio ordenador supremo que, suficiente por si, confere ordem ao ser das coisas, sem demandar que suas razões sejam questionadas. ${ }^{33}$ Daí que mais valha aos cronistas encomendarem-se a ele ou aos seus intermediários. É o que faz, entre outros, o também cronista avisino Frei João Álvares (14-/1484), na Crónica do Infante Santo, ao declarar que decidiu contar a história do martírio do Infante D. Fernando (1402-1443), "nom em fingidas patranhas nem em ouçiosas fabulas", porque contava tomar "por testymunha nosso Senhor Deus que he caminho, verdade e vida...”. É também o que faz Duarte Galvão, ao abrir sua Crónica de El-Rei D. Afonso Henriques encomendando-se ao Espírito Santo para que lhe conceda a graça para narrar os feitos dos reis portugueses "em deuida lembramça". ${ }^{44}$ Essa crença em um princípio condutor que dispensa justificação ampara a representação cronística da realidade, isto é, a ordenação buscada é já supostamente preestabelecida e não guiada por um recorte, de onde a importância conferida à cronologia.

Nesses relatos movidos pela busca de uma ordem superior inscrita no plano dos acontecimentos, merecem destaque alguns aspectos, como: a narrativa construída em torno de um tema central, seja um reinado, seja a vida de um cavaleiro exemplar, sejam os desdobramentos de uma conquista ou reconquista territorial com os inevitáveis ornamentos bélicos; um ponto de partida temporal, conduzido por um desses mencionados referenciais; um palco de realizações predominantemente urbano ou guerreiro; e personagens centralizadores do relato. Mas há um ponto que merece também destaque na

\footnotetext{
${ }^{32}$ Hayden White, El Contenido de la forma, p. 21-39. Sobre essas formas de representação da realidade, ver também: Bernard Guenée, Histoire et culture historique dans l'Occident médiéval e, relativamente a Portugal, Joaquim Veríssimo Serrão, A historiografia portuguesa. Doutrina e crítica.

${ }^{33}$ Sobre este ordenador, ver Etienne Gilson, L'esprit de la philosophie médiévale, Paris, Librairie Philosophique J. Vrin, 1989, p. 80.

${ }^{34}$ Cf. Frei João Álvares, Chronica do Infante Santo D. Fernando, Ed. Mendes dos Remédios, Coimbra, F. França Amado - Editor, 1911, p. 2 e Duarte Galvão, Crónica de El-Rei D. Afonso Henriques, Lisboa, Imprensa Nacional Casa da Moeda, 1995, p. 9.
} 
sustentação da história dos cronistas: a preocupação em legitimar seu relato a partir das fontes que utilizaram, escritas ou testemunhais, e da evocação, segundo o citado White, de autoridades, a saber, Deus, o defensor ou protetor - em geral o rei ou algum infante -, os clássicos e a sua própria. Deus surgia como fundamento primeiro, último e sem necessidade de justificação da narrativa, ou seja, como o legitimador metafísico. O protetor surge como aquele que legitima e apoia por meios concretos, inclusive materiais. Os clássicos vêm trazer o indispensável respaldo da tradição, em um tempo em que os valores considerados superiores se amparavam sobretudo no que já tinha sido, inclusive através da reprodução integral. E o próprio cronista, enfim, surge como autoridade que, por seu compromisso assumido com a verdade, é o que se encontra em melhores condições para estabelecê-la. Ele era uma espécie de "Cronista Ideal", capaz de apresentar uma descrição completa de um acontecimento, de registrar tudo o que aconteceu na ordem em que aconteceu. ${ }^{35}$ No entender dos "ajuntadores" de histórias do final da Idade Média, o que era direito e verdadeiro dependia em grande parte da consciência, capacidade e honestidade daquele que escrevia. É isso que Fernão Lopes sugere ao advertir o historiador para que ponha "adeparte toda afeiçom" pela terra onde nasceu, a fim de não favorecer a imagem dos seus conterrâneos, esquecendo as "comtrairas cousas" que também compõem as histórias verdadeiras. Ainda que, entretanto, seus critérios para o estabelecimento dessa verdade nem sempre sejam explicitados, provavelmente em razão de se deixarem conduzir pelo referido princípio metafísico, a motivação e empenhamento pessoal para encontrar a ordem verdadeira são reafirmados diversas vezes ao longo dos textos e sustentam, em grande parte, a autoridade dos cronistas.

Pelo que se disse, já é possível notar um distanciamento da forma de representação da realidade possível ou ambicionada nos anais, uma vez que o impulso narrativo envolve um desejo de reprodução da realidade alcançável através da atenção aos sinais divinos e do apoio das referidas autoridades. Os cronistas defendiam, assim, a possibilidade de um acontecimento ser atestado de forma absoluta no seu fazer histórico e, conquanto contemplem que sua construção não é integral - ou porque faltam fontes, ou porque estas são

${ }^{35}$ Só a crença de que o sentido estava fixado nas próprias coisas poderia levar à convicção na possibilidade de alcançar esta reprodução perfeita. A representação, como lembra Foucault, se dava como repetição: "teatro da vida ou espelho do mundo". Cf. Michel Foucault, As Palavras e as Coisas: uma arqueologia das ciências humanas, São Paulo, Martins Fontes, 1985 , p. 33. 
omissas em determinados pontos e tendenciosas em outros -, não estabelecem relações explícitas entre a impossibilidade da integralidade e a impossibilidade de alcance do passado como teria ocorrido, ${ }^{36}$ e mais, não viam como problema o fato de a busca de fidelidade aos acontecimentos não anular seu envolvimento valorativo. Tais considerações, entretanto, são retrospectivas, ou seja, as configurações do gênero e os problemas levantados estão aqui contemplados tendo em conta os desdobramentos posteriores do fazer histórico e das reflexões sobre este. E, nessa mesma linha, é relevante notar igualmente como a busca do acontecimento absoluto não descartava um elemento que, a partir do século XIX, começa a ser pensado como incompatível com esse alvo: a intenção moralizadora. Intenção que, poder-se-ia dizer, tanto opera na própria ordenação narrativa - motivada pelo desejo de identificação com a sociedade descrita - quanto visa futuros leitores ou ouvintes.

À história medieval cabia, além de registrar com fidelidade os acontecimentos, oferecer uma série de exemplos dos quais se deveria fugir e outros a serem imitados. A rememoração do passado, ancorada no acontecimento e, por isso mesmo, pretensamente exata, era, pois, modelada pela função moralista, levando a uma seleção segundo um critério de edificação. ${ }^{37}$ Nesse ${ }^{36} \mathrm{O}$ combate ao entendimento do acontecimento como aquilo que realmente aconteceu é uma das ênfases da historiografia francesa do século XX e é mais radicalmente realizado por Paul Veyne, quando este o vincula à intriga, considerando que um acontecimento só é histórico na intriga, na trama histórica. Cf. Paul Veyne, Como se escreve a história, 4. ed, Brasília, UNB, 1998.

${ }^{37}$ Cícero entendia a história como "mestra da vida" e esse seu caráter pedagógico justificava as imortalizações que empreendia. Nesse sentido, a história podia se constituir num repertório de exemplos políticos e morais. Era a "verdade ética" que deveria estar na mira do historiador (Historia vero testis temporum, lux veritatis, vita memoriae, magistra vitae, nuntia vetustatis, qua voce alia nisi oratoris immortalitati commendatur?). Cf. De oratore, II, 9, 36, in: M. T. Cicerón, El Orador, ed. bilíngue, texto revisado e traduzido por A. Tovar e A. R. Bujaldón, Barcelona, Alma Mater, 1967. Essa noção de história como mestra da vida foi sintetizada por Koselleck no ensaio "Magistra Vitae", do célebre Futuro passado, em que ele mostra que até o séc. XVIII existiu a teoria de que da história do passado se podia projetar o futuro. O conhecimento do passado e a previsão do futuro estavam unidos em um horizonte de experiências, dentro do qual não pode suceder nada verdadeiramente novo. Experiências alheias instrutivas e edificantes deviam compor a história, levando os homens a repetir os êxitos passados e afastarem-se dos erros. Se esse topos da "história como mestra da vida", como exemplo, se dissolve no final do século XVIII, a sua durabilidade e plasticidade é notada pelo historiador da "história dos conceitos", que mostra como vai de Cícero, passa pela experiência cristã da história, por Maquiavel e por Bodin até que, com a revolução francesa, esse sentido se desvanece, abrindo espaço para um futuro inaudito, um futuro alimentado pela revolução e já não por um passado familiar. Cf. R. Koselleck, História Magistra Vitae - Sobre a dissolução do topos na história moderna em movimento, in: Futuro passado, contribuição à semântica dos tempos históricos, Trad. Wilma Patrícia Maas e Carlos Almeida Pereira, Rio de Janeiro, Contraponto; Editora PUC/Rio, 2006, p. 41-60. 
sentido, o que para a história que se quer científica poderia parecer contraditório, a saber, a aproximação entre pretensão de neutralidade ou de fidelidade aos eventos e o comprometimento valorativo, para esses cronistas medievais era perfeitamente aceito, pois esses dois traços funcionavam como arrimos de uma verdade construída sobre o acontecido mas atenta ao que estava por acontecer. Se um dos empenhos desses narradores era em fazer coincidir o acontecimento e o escrito, o outro era em conduzirem-se por ideais edificantes, isto é, pelo que esperavam que ficasse para os tempos vindouros. Para Pina, os livros, especialmente os de "estória", que continham os feitos e os costumes dos reis e príncipes, eram "um vivo espelho dos bons exemplos, e das cousas passadas". O cronista considerava-os "conselheiros mortos", sempre prontos a ensinar e a dar "verdadeiros e sãos conselhos, mui livres e isentos das paixões dos Conselheiros vivos (...)". E antes dele, para ficarmos por apenas alguns exemplos, o supracitado conde de Barcelos tinha afirmado que as histórias do passado foram escritas para que os que depois "veessen trabalhassem de fazer bem per exemplo dos bõos e que pello dos maaos se castigassem". ${ }^{38} \mathrm{Na}$ mesma linha, tinha asseverado Zurara que os benefícios da história estavam em ela configurar-se como "memoriall das uirtuosas obras" e como "espelho" no qual, recomendava "Socrates gramde philosofo", os jovens deveriam se mirar sempre, "por tall que os boõs feitos de seus amteçessores fossem a elles proueitoso emsino (...)".

É nesse jogo de tempos, passado, presente e futuro, ${ }^{40}$ que devem ser entendidas essas narrativas. Os cronistas não perdem a oportunidade - ou não deixam de criá-la - de registrar ações virtuosas. Sua atenção recobre, nesse sentido, as várias dimensões da existência dos personagens centralizadores do relato: deveres, prazeres, costumes, qualidades, relações com servidores e familiares e compromissos com a governação, ${ }^{41}$ aspectos que são organizados a partir de determinados eixos condutores, como a tão proclamada desigualdade natural. Para não ir além dos exemplos portugueses, recorde-se que o infante

${ }^{38}$ Sobre o critério de edificação, ver Teresa Amado, Fernão Lopes, contador de história, Lisboa, Estampa, 1991, p. 13. Cf. Rui de Pina, Crónica de D. Afonso V, p. 583 e Crónica Geral de Espanha de 1344, p. 5.

${ }^{39}$ G. E. de Zurara, Crónica da Tomada de Ceuta, Ed. Francisco Maria Esteves Pereira, Coimbra, Academia das Sciencias de Lisboa, 1915, cap. XXXVIII, p. 117-118.

${ }^{40}$ Esse mesmo jogo, como ressalta o referido Koselleck, se altera com a revolução francesa, já que o futuro já não é projetado pelo passado. Cf. R. Koselleck, op. cit., p. 41-60

${ }^{41}$ Cf. Ana Isabel Buescu, Imagens do Príncipe. Discurso normativo e representação (1525-49), Lisboa, Edições Cosmos, 1996, p. 64. 
D. Pedro, no capítulo inicial de O Livro da Virtuosa Benfeitoria, considera que Deus estabeleceu "graaos em as cousas que fez" e também na mais completa compilação de direito do século XV, as Ordenações Afonsinas, uma passagem diz que Deus, quando fez as criaturas, "nom quiz que todas fossem iguaaes (...) e hordenou cada huuã em sua virtude, e poderio departidas (...)". Sob esse condutor, virtudes e pecados aparecem definidos tendo em conta os lugares sociais ocupados pelos personagens das crônicas. Assim, como esses personagens eram nobres, a pedagogia dos cronistas incidia acima de tudo sobre a esfera das realizações, governativas e guerreiras, porém, os cronistas procuraram atentar também para as atividades e preocupações habituais dos defensores $^{42}$ e para as relações que estabeleciam com os que os rodeavam.

Alguns tópicos são dignos de nota no que diz respeito à governação. Não perder de vista o exercício da justiça e os desembargos era apontado como digno dos bons governantes. D. Pedro I, por exemplo, ocupava a maior parte do seu tempo, segundo Fernão Lopes, em fazer justiça e desembargos do Reino, embora também caçasse e festejasse da forma como era habitual naquele tempo e como também era conveniente para repor as energias gastas no trabalho governativo - "reparar o entender" e ajudar na preservação das habilidades guerreiras, como dizia D. João I. Desse modo, entre funções e prazeres deslocavam-se reis e nobres, contudo, na cronística, estes últimos são contemplados em função daquelas, pois os prazeres aparecem justificados tão somente quando de alguma forma ajudam ou não atrapalham no cumprimento daquilo para que estavam destinados.

Da mesma forma que os prazeres, também a aparência - compleição, forma de vestir, gestos e forma de falar e sinais de devoção - deveria ser trabalhada tendo em vista a função desempenhada no seio da sociedade. Nos homens, a robustez e a proporcionalidade surgem como as qualidades mais louváveis; nas mulheres, por sua vez, mais que a beleza, contavam as virtudes morais, porém, nada mal se os dois tipos de virtudes estivessem conjugados, como em D. Leonor de Lencastre (1458-1525), que reuniu uma aparência

\footnotetext{
${ }^{42}$ Respectivamente Infante D. Pedro, D. Duarte, O Lioro da Virtuosa Benfeitoria ..., cap. I, p. 533; Ordenações Afonsinas, 5 vols. Reprodução «fac-simile» da edição da Real Imprensa da Universidade de Coimbra, 1792, Lisboa, Fundação Calouste Gulbenkian, Livro II, Tit. XL, p. 293. De acordo com as Ordenações Afonsinas, Livro I, Tit. LXIII, a definição serve principalmente para os cavaleiros, sendo que o rei, em "virtude de sua preheminencia enclude em sy naturalmente a honra, e hordem da Cavallaria (...)" (p. 365). Sobre o termo, veja-se também A. H. de Oliveira Marques, Portugal na crise dos séculos XIV e XV, Lisboa, Presença (Coleção Nova História de Portugal), 1987, p. 236-238.
} 
agradável e uma postura adequada. Rui de Pina descreve que a sua beleza era resultado da harmonia entre o seu corpo e a sua alma. ${ }^{43}$

Papel de relevo na imagem geral desempenhavam os trajes. E, neste caso, a magnificência era algo que os nobres não podiam dispensar. D. Duarte, para "boõ enxempro de os grandes e nobres de seu Regno nom fazerem despesas desmasiadas em vestidos e arrêos sobejos", teve de submeter-se a algumas restrições, mas garantiu uma cota para que a sua dignidade real não ficasse abalada. D. João II foi rei "que sempre se prezou d'andar bem, e ricamente vestido (...)", mas, também para evitar os excessos dos fidalgos no uso de sedas e brocados, se sujeitou a algumas contenções, só as suspendendo durante as festas do casamento do infante D. Afonso (1475-1491). As roupas dos reis e nobres deveriam ser sobretudo ricas, pois a riqueza era sinônimo de realeza e nobreza. ${ }^{44}$ Mas nem só luxo cabia aos nobres; a honestidade no vestir é também mencionada por Pina em louvor dos seus retratados.

Completava ainda a imagem geral dos nobres e o rol das suas preocupações os movimentos e a linguagem. Da mesma forma que Fernão Lopes acerca dos seus retratados, Zurara parece acreditar que os gestos e as palavras, além de revelarem o caráter da pessoa que os expressa, eram distintivos da sua posição social, razão pela qual convinha que fossem moderados. Talvez por isso tenha insistido em descrever aquele cuja vida julga ser "proveitoso ensino de todos os Principes", o infante D. Henrique (1394-1460), como homem que sabia honrar a condição de cada uma pessoa com o "seu gesto assossegado" e a sua "palavra mansa", traços aparentes de uma personalidade que não conhecia "odio nem má vontade contra alguma pessoa, por grave erro que lhe fizesse (...)". Também por isso, provavelmente, Pina, ao escrever que o infante D. Pedro ficava com uma cara "muy temerosa" quando se irritava, procure ressalvar que não era por muito tempo, "cá por syso ou condiçam natural, logo se lembrava de mansydam e temperança (...)”. Comedimento que o pouco exemplar D. Afonso XI de Castela (1311-1350), "muy solto da lingoa”, não se preocupava em guardar, pois costumava dizer muito mais do que devia. Quanto às palavras, não interessava tanto o aspecto físico da voz,

${ }^{43}$ Cf. Rui de Pina, "Crónica de D. João II”, in: Crônicas, Ed. M. Lopes de Almeida, Porto, Lello \& Irmão, 1977, cap. LXIX, p. 1020.

${ }^{44}$ D. Sancho II, na descrição de Pina, é apresentado como um rei que tinha por hábito usar vestidos honestos, mas que mais se assemelhavam aos trajes de religiosos do que de rei, hábito que ajudava a compor a personalidade de um rei que não teve a "verdadeyra fortaleza que pera Rey era muy necessaria (...)". Cf. Rui de Pina, "Crónica de D. Sancho II”, in: Crônicas, Ed. M. Lopes de Almeida, Porto, Lello \& Irmão, 1977, cap. I, p. 131-132. 
mas principalmente o conteúdo do que é dito e a forma como o é. Fernão Lopes, por exemplo, refere rapidamente que D. Pedro I era muito gago, mas não é tão ligeiro ao descrever a decência no falar de D. João I. ${ }^{45}$

Lugar de grande destaque na vida dos nobres descritos por Fernão Lopes, Zurara e Pina ocupa a devoção. Os rótulos de fiel católico, mui devoto e outros do gênero são qualificativos elogiosos frequentemente requisitados pelos cronistas para descrever os reis e senhores. Depreende-se, nas diversas passagens em que este aspecto é contemplado, que, especialmente no caso dos senhores e dos reis, o sentimento religioso e as demonstrações de fé eram peças complementares. Determinadas ações, tais como de cumprimento dos mandamentos cristãos, de defesa da fé católica, de criação de novos espaços sagrados e de preservação dos antigos, faziam parte da obrigação dos nobres. Nesse sentido, a dedicação íntima a Deus, a prática cotidiana da devoção e os benefícios materiais à Igreja compunham a religiosidade desses homens.

Nesse contexto de fundação da "nacionalidade" em Portugal, vale concluir, a escrita - como ocorre também em outras partes - cumpre um papel decisivo e a escrita em língua vernácula se impõe como a mais legítima para traduzir as realidades presentes, mais especificamente, para traduzir os interesses particulares dos reinos e dos monarcas. ${ }^{46}$ Os escritos produzidos nesse momento, como lembram Joël Blanchard e Jean-Claude Mühlethaler, ${ }^{47}$ em geral não se libertam do político ou, ao menos, de referências a ele, e os escritos cronísticos ou históricos, especialmente, configuram-se como escritos de poder por excelência, já que são eles os responsáveis por consolidar uma certa imagem dos reis e da sua administração. ${ }^{48}$ Para os governantes do

${ }^{45}$ Cf. Respectivamente Rui de Pina, "Crónica de D. João II", in: Crônicas, Ed. M. Lopes de Almeida, Porto, Lello \& Irmão, 1977, cap. LXIX, p. 1020; Rui de Pina, "Crónica de D. Duarte", in: Crônicas, Ed. M. Lopes de Almeida, Porto, Lello \& Irmão, 1977, cap. VII, p. 504; Rui de Pina, "Crónica de D. João II”, cap. LXXXII, p. 1031; Rui de Pina, "Crónica de D. João II", cap. XXIII, p. 939; Rui de Pina, "Crónica de D. Sancho I”, In: Crônicas, Ed. M. Lopes de Almeida, Porto, Lello \& Irmão, 1977, cap. II, p. 13; Rui de Pina, "Crónica de D. Sancho I", cap. IV, p. 23-25; Rui de Pina, "Crónica de D. Afonso V”, cap. CXXV, p. 753; Rui de Pina, "Crónica de D. Afonso IV", cap. XLVIII, p. 419. Cf. Crônicas dos Sete Primeiros Reis de Portugal, v. II, p. 296; Fernão Lopes, Crónica de D. Pedro I, cap. I, p. 7 e Fernão Lopes, Crónica de D. João I. Parte Segunda, prólogo, p. 2.

${ }^{46}$ Cf. C. Orcástegui e E. Sarasa, La historia en la Edad Media. Historiografia e historiadores en Europa Occidental: siglos V-XIII, p. 226-228.

${ }^{47}$ Joel Blanchard and Jean-Claude Mühlethaler, Ecriture et pouvoir àl'aube des temps modernes, p. 2.

${ }^{48}$ Alain Bresson considera que "o nascimento do Estado, nomeadamente o Estado complexo, está ligado ao nascimento e ao uso da escrita”. Alain Bresson; Anne-Marie Cocula ; 
período, a condição da escrita como forma de poder, que remonta a Platão e Aristóteles, foi intensamente revivificada, e os homens que dela se ocuparam não só tornaram efetivo tal potencial político das crônicas como também se vincularam indissoluvelmente ao poder ao qual serviram. Tendo, pois, em conta o quadro de incursões moralizantes acima descrito - que é muito mais amplo do que essas breves amostras podem fazer crer -, pode-se dizer que a atenção dos cronistas, inspirada no modelo bíblico, no modelo aristotélicomedieval filtrado nas obras de São Tomás de Aquino e de Egídio Romano e no modelo clássico, conduzia-se por uma dupla vertente: a imagem do príncipe como homem e como governante. ${ }^{49}$ Ainda de alguma forma inspirados pelos ensinamentos de Sêneca, os cronistas medievais construíram suas histórias considerando que os homens de bem, os governantes sobretudo, deveriam ser tomados como modelo, ${ }^{50}$ razão pela qual apresentam diversos modelos ao longo das narrativas, modelos esses organizados a partir de indicações de como deveria ser a atuação dos nobres e reis em situações difíceis e de como deveriam proceder nas diversas circunstâncias da sua existência e em relação àqueles que os rodeavam, fossem familiares ou servidores.

À história medieval cabia, por fim, como se buscou aqui examinar, além de registrar com fidelidade os acontecimentos, oferecer uma série de exemplos dos quais se deveria fugir e outros a serem imitados, ${ }^{51}$ pois o empenho em fazer com que as palavras correspondessem exatamente aos fatos não se mostrava incompatível com o compromisso moralizador. Se para nós parece discutível tal conjugação, para os cronistas de então, ao contrário, ela era o fundamento do seu realismo e da sua verdade.

Christophe Pébarthe, L'Écriture Publique du Pouvoir, Bordeaux/Paris, Ausonius/Diffusion de Boccard, p. 12 (tradução minha). Também trata da questão Bernardo Vasconcelos Souza, «Medieval Portuguese Royal Chronicles. Topics in a Discourse of Identity and Power", EJPH, Vol. 5, number 2, Winter 2007.

${ }^{49}$ Cf. Ana Isabel Buescu, Imagens do Príncipe. Discurso Normativo e representação (1525-49), Lisboa, Edições Cosmos, 1996, p. 64.

${ }^{50}$ A máxima de Epicuro citada por Sêneca em Cartas a Lucílio dizia: "devemos eleger um homem de bem como modelo e tê-lo sempre diante dos olhos, de modo a vivermos como se ele nos observasse, a procedermos como se ele visse os nossos actos". Sêneca, Cartas a Lucílio, Trad. J. A. Segurado e Campos, Lisboa, Fundação Calouste Gulbenkian, 1991, Livro I, carta 11, p. 32.

${ }^{51} \mathrm{O}$ vício deveria ser evitado por ser, como ensinavam os estoicos, o momento em que o indivíduo se mostrava deformado, afetado e perdido dentro de uma paixão que o possuía por inteiro. Cf. M. Foucault, La Hermenéutica del sujeto, Trad. Horacio Pons, Buenos Aires, Fondo de Cultura Económica, 200, p. 110. 